\title{
On the role of normative influences in commercial virtual communities
}

Citation for published version (APA):

Wiertz, C., de Ruyter, J. C., \& Streukens, A. C. P. (2003). On the role of normative influences in commercial virtual communities. METEOR, Maastricht University School of Business and Economics. METEOR Research Memorandum No. 017 https://doi.org/10.26481/umamet.2003017

Document status and date:

Published: 01/01/2003

DOI:

10.26481/umamet.2003017

Document Version:

Publisher's PDF, also known as Version of record

\section{Please check the document version of this publication:}

- A submitted manuscript is the version of the article upon submission and before peer-review. There can be important differences between the submitted version and the official published version of record.

People interested in the research are advised to contact the author for the final version of the publication, or visit the DOI to the publisher's website.

- The final author version and the galley proof are versions of the publication after peer review.

- The final published version features the final layout of the paper including the volume, issue and page numbers.

Link to publication

\footnotetext{
General rights rights.

- You may freely distribute the URL identifying the publication in the public portal. please follow below link for the End User Agreement:

www.umlib.nl/taverne-license

Take down policy

If you believe that this document breaches copyright please contact us at:

repository@maastrichtuniversity.nl

providing details and we will investigate your claim.
}

Copyright and moral rights for the publications made accessible in the public portal are retained by the authors and/or other copyright owners and it is a condition of accessing publications that users recognise and abide by the legal requirements associated with these

- Users may download and print one copy of any publication from the public portal for the purpose of private study or research.

- You may not further distribute the material or use it for any profit-making activity or commercial gain

If the publication is distributed under the terms of Article $25 \mathrm{fa}$ of the Dutch Copyright Act, indicated by the "Taverne" license above, 


\title{
ON THE ROLE OF NORMATIVE INFLUENCES IN COMMERCIAL VIRTUAL COMMUNITIES
}

\author{
Caroline Wiertz ${ }^{1}$ \\ Ko de Ruyter \\ Sandra Streukens
}

Maastricht University

Acknowledgements: The authors are grateful to Tor Andreasson and Benedict Dellaert for their valuable feedback on earlier versions of this paper.

${ }^{1}$ Contact Author. Maastricht University, Faculty of Economics and Business Administration, Department of Marketing and Marketing Research,

PO Box 616, 6200 MD, Maastricht, The Netherlands. Phone: +31 433883716.

Email: c.wiertz@mw.unimaas.nl 


\title{
ON THE ROLE OF NORMATIVE INFLUENCES IN COMMERCIAL VIRTUAL COMMUNITIES
}

\begin{abstract}
The potential to reconcile economic benefits to the firm with the social needs of customers has made commercial virtual communities a popular tool for companies to support their core products/service with a value-added service option. An important key to the success of such a virtual community is the behavior of its members. In this paper, we develop a framework of pro-social behavior (i.e., community citizenship behavior and contribution intentions) for understanding and explaining the motivation of virtual community members to actively participate in and care for the community. We show that the main determinants of pro-social behavior are the social norm of reciprocity and the personal norm of obligation. Reciprocity, in turn, is impacted by the value of the information and the socio-emotional support exchanged by the virtual community members.
\end{abstract}

Keywords: virtual communities, norms, pro-social behavior, citizenship behavior 


\section{Introduction}

The pervasiveness of the Internet is driving many companies to widen their offering of electronic services. In order to prevent the risk of depersonalization inherent in digital environments, interactive technologies, such as e-mail, chat sessions, and video conferencing, enable companies to combine 'high tech' with 'high touch' (Naisbitt, Naisbitt, \& Philips, 2001). By allowing for the integration of these various channels of communication, the virtual community represents one of the most interesting developments of the Net (Balasubramanian \& Mahajan, 2001; Kozinets, 1999). The Pew Internet \& American Life Project estimated that in 2001, $84 \%$ of the American Internet users have contacted an online consumer group. Of these users, $79 \%$ identified at least one particular virtual community with which they stay in regular contact (http://www.pewinternet.org). Through the support of textual "conversations" enabled by modern communication technology, virtual communities function as social spaces in which basically any topic can be discussed and in which participants actively create both informational and socio-emotional exchanges (Burnett, 2000). Virtual communities, which allow people to interact and cluster with similar others, bring back a sense of social belonging to the frequently sterile online environment. In other words, the high interactivity between community members has the potential to transform simple online transactions into memorable 'experiences' (Mathwick, Malhotra, \& Rigdon, 2001). The opportunity to integrate social objectives with economic benefits to the firm has made virtual communities an interesting tool for companies to provide added value to their customers. Essentially, virtual communities can be used by companies to deliver an additional service by providing customers with a place where they can gather quality information, forge relationships, and conduct transactions. The single most important ingredient in a virtual community is the active involvement of its members (Cothrel \& Williams, 1999; McWilliam, 2000). Through the collaborative 
discussions and mutual learning experiences of the community members, supported by the resources made available by the community sponsor, informational and social capital is created. As the community members not only consume, but also collectively co-produce the informational and socio-emotional value of the community, they in fact provide a service to each other and take on the role of 'partial employees' (McWilliam, 2000). In order to understand what drives the emergence of a critical mass of active and caring community members that is necessary to keep the virtual community alive, an in-depth analysis of the motivations of its members is required. The maximization of self-interest does not adequately explain why people contribute to the virtual community as opposed to lurking or free-riding (McLure Wasko \& Faraj, 2000). Rather, an explanation may be found by examining the relationships between individuals and groups (Bagozzi \& Dholakia, 2002). The explanatory basis for such relationships in traditional face-to-face groups consists of normative influences on behavior (Miniard \& Cohen, 1983). In the online environment however, scholars disagree whether norms play a sub- or superordinate role in determining behavior (Kiesler \& Sproull, 1992; Johnson, 2001; Bernard, 2002). We argue that, at least in the context of virtual communities, normative influences are successfully transferred into the online world. Social and personal norms are expected to be key drivers of pro-social behavior, which is performed by individuals with the expectation that it will benefit other persons, groups or organizations (Brief \& Motowidlo, 1986). Pro-social behavior, which we conceptualize as helping, care for and active participation in the virtual community, in turn ensures the success and perpetuity of this auspicious new electronic medium.

Despite the plethora of investigations on the phenomenon of virtual communities over recent years, the relevant issue of how to promote desired behaviors of community members to ensure the survival and success of the community in a commercial context has not been rigorously addressed so far. Most published work on how companies can profit from virtual 
communities is conceptual in nature (Balasubramanian \& Mahajan, 2000; McWilliam, 2000; Muniz \& O’Guinn, 2001; Rothaermel \& Sugiyama, 2001), while existing research pertains predominantly to sociological questions concerning the history and conceptualization of virtual communities (Etzioni \& Etzioni, 1999; Fischer, Bristor, \& Gainer, 1996; McLure Wasko \& Faraj, 2000). In addition, most existing studies make use of qualitative techniques and lack empirical evidence (Kozinets, 1999; 2002). Also, previous studies on virtual communities have been conducted without much guidance from pre-existing theories. With the notable exception of Bagozzi and Dholakia (2002), no systematic research in marketing has examined the motivations of active customer participation in commercial virtual communities. Therefore, in this paper, we develop and empirically test a framework of prosocial behavior for understanding and explaining the desired behaviors of community members, which lead to the success of a commercial virtual community. We contribute to the existing literature by evaluating the impact of the theory of norms in the online world and by developing insights in to the mechanisms of pro-social behavior in virtual communities. Furthermore, this study highlights the importance of the two main benefits exchanged in virtual communities, namely the value of information and socio-emotional support, in triggering the awareness of the norms governing pro-social community behavior.

The paper is structured as follows. To achieve clarity in the use of terminology, we first introduce the general concept of commercial virtual communities. We proceed with a review of the relevant literature on economic and social exchanges in order to identify the key determinants of desired member behaviors that determine the success of a commerciallyoriented virtual community. After constructing a conceptual framework, we subsequently report on the results of a study conducted in a virtual community setting aimed at empirically testing the framework. We conclude the paper with directions for future research and a discussion of the implications for management. 


\section{Background and Conceptualization of the Virtual Community}

While the community phenomenon has been the focus of many sociological and psychological inquiries, it has also been one of the most elusive concepts (Bell \& Newby, 1974; Etzioni \& Etzioni, 1999; Fernback \& Thompson, 1995; Puddifoot, 1995; Rothaermel \& Sugiyama, 2001). Even though numerous articles and books have been dedicated to the collection and analysis of differing definitions of community (Hillery, 1955; Fowler, 1981), consensus about a definite theory has not been reached. One of the earliest, and probably most influential researchers who studied the community phenomenon was Ferdinand Toennies (1912). He made a basic distinction between Gemeinschaft, a small, emotional and exclusive community, and Gesellschaft, the larger, rational, individualistic society, and claimed that industrialization and modernity fostered Gesellschaft to the ravage of traditional communities. Contemporary researchers examining virtual communities argue that their rapid growth is a consequence of a sense of loss at the personal and business level triggered by the destruction of Gemeinschaft and the resulting shift to Gesellschaft (Fernback \& Thompson, 1995; Muniz \& O'Guinn, 2001). In order to anchor themselves, find support, and regain a sense of identity, people cluster online with similar others and support each other by exchanging informational and especially socio-emotional support (Bressler \& Grantham, 2000; Fernback \& Thompson, 1995; Jones, 1997). In this way, virtual communities originally began to form as social entities with the aim to bring back a sense of Gemeinschaft. In a commercial context, Hagel and Armstrong (1997) propose that virtual communities fulfill four types of consumer needs:

the sharing of a specific interest (e.g. at Powderhausen, a virtual community for sowboarders), the building of relationships (e.g. at Medicity, a medical community where members share similar destinies), the experience of fantasy (e.g. in the popular Lord of the Rings communities), and the conduct of transactions (e.g. at Amazon or E-bay). As the four 
needs are clearly not mutually exclusive, community sponsors should try to meet all of them simultaneously wherever possible (Hagel \& Armstrong, 1997). Due to the diversity of communities which can be found on the Internet, the attempt to define the term 'virtual community' evokes at least as much disagreement as the definition of traditional face-to-face communities. For the purpose of this paper, we define commercial virtual communities as online aggregations of consumers who collectively co-produce and consume content about a commercial activity that is central to their interest by exchanging informational and socioemotional value.

The inherent benefits of commercial virtual communities are the social and affective components that they add to the traditionally impersonal self-service technologies which are characteristic in many online environments. While many companies have successfully implemented online self-service options to increase customization and flexibility, the need of consumers for human contact has for a long time been ignored in the online world (Albrecht \& Zemke, 2001). Virtual communities offer the potential of interactive and collaborative exchanges, which can add experiential value to simple online transactions (Mathwick, Malhotra, \& Rigdon, 2001) by allowing for many-to-many communication. A company that sponsors a virtual community for its customers can expect several benefits. In addition to increased loyalty to the brand (McAlexander, Schouten, \& Koenig), the company has the opportunity to monitor the ongoing peer-to-peer conversations in order to gather insights about the ideas, trends and problems that their customers deal with, as well as collect information about how its customers evaluate the products and services offered by the sponsor as well as the competition. In addition, consumers can exchange information and build up emotional bonds with similar others. The resulting informational and socioemotional value benefits all members and may be perceived as an additional service, which is in fact provided by the community members themselves, but still positively associated with 
the sponsoring company. In such a way, the sponsoring company can benefit from positive branding effects without 'having to do the work' (McWilliam, 2000; McAlexander, Schouten, $\&$ Koenig, 2002). Thus, the success of such a commercial virtual community depends on the active participation and care of the members of the community. It is therefore essential to understand the mechanisms that govern pro-social behavior in the context of virtual communities. Previous research has suggested that people tend to participate in virtual communities due to a sense of moral responsibility, which results in a feeling of duty toward the community as a whole and its individual members (McLure Wasko \& Faraj, 2000; Muniz \& O’Guinn, 2001). As purely economic benefits cannot adequately explain this sense of moral responsibility, an investigation of normative influences at both the social and the personal level will be used to understand the pro-social behaviors displayed by members of commercial virtual communities.

\section{Normative Influences}

Traditionally, marketers have tried to explain consumer behavior in terms of mainly economic and psychological incentives and neglected the potential influence of normative forces. In recent years, however, there has been an accumulative body of literature, which has recognized that consumer behavior is also largely driven by social and personal norms. Prosocial behaviors displayed by consumers, such as donating money (Diamond \& Kashyap, 1997), helping (Price, Feick, \& Guskey, 1995); spreading positive word-of-mouth (Puffer, 1987), or volunteering (Fisher \& Ackerman, 1998), cannot be adequately explained by economic motives alone. Pro-social behaviors are purely social, positive acts carried out with the expectation to benefit others. People often behave altruistically and pro-socially, contributing to the welfare of others without apparent compensation or maximization of personal outcomes. These behaviors may be explained by the theory of norms. Norms specify 
expectations about how an individual should or ought to behave, and are enforced by the promise of rewards and the threat of sanctions (Cialdini, Kallgren, \& Reno, 1991). These rewards or sanctions can either be administered by the social group or by the individual itself (Schwartz, 1977). Therefore, norm theory distinguishes between social and personal norms.

\section{Social Norms}

Social norms are characterized by perceptions, attitudes and values that are commonly accepted by a social group. Members are expected to behave according to these social norms, and compliance is enforced by social rewards, such as receiving praise and creating a good impression, and social punishments, such as negative verbal expressions of disappointment (Schwartz, 1977; Osterhus, 1997). Although they are usually not written down or explicitly stated, social norms have a strong influence on behavior, especially when this behavior is observable to other group members (Feldman, 1984). It has been argued that social norms, such as reciprocity, parity, and fairness (Schwartz, 1977) are some of the main drivers of prosocial behavior. Especially the norm of reciprocity has been shown to play a major role in initiating altruistic behaviors (Gouldner, 1960; Schwartz, 1977; Smith, 1980; Diamond \& Kashyap, 1997). As defined by Gouldner (1960), the norm of reciprocity specifies that people should help those who have helped them; in other words, a return must be given for the benefits received. Furthermore, the reciprocity norm stipulates that the value of that return should be "roughly equivalent" (Gouldner, 1960, p. 171) to what has been obtained from the other party. Recipients of beneficial actions feel a sense of indebtedness, which leads to a motivation to alleviate this indebtedness through reciprocation (Gatignon \& Robertson, 1986). These efforts of reciprocation result in a large variety of pro-social behaviors, which in turn will be reciprocated by the benefiting party. In this way, reciprocity is the "vital principle" of social stability (Gouldner, 1960, p. 161). 


\section{Social Norms in Virtual Communities}

Also in the context of virtual communities, it has been suggested that the norm of reciprocity is prevalent and governs the social interactions between members. McLure Wasko and Faraj (2000) investigated helping behavior in three virtual communities and found that reciprocity was a main driver of pro-social behavior. Giving back to the community in return for help was the most important reason why people participate in a virtual community. Furthermore, many members noted that they were willing to help other members because it would have been nice to have had some help at some point in the past. Interestingly, in virtual communities, members do not seem to expect that benefits will be received from the same individual that they have helped previously. Rather, virtual communities may support a form of "generalized reciprocity" (Constant, Sproull, \& Kiesler, 1996; McLure Wasko \& Faraj, 2000), where members expect that help given to one individual will be reciprocated by someone else than the original recipient of the help.

\section{Personal Norms}

In addition to social norms, personal norms have been shown to be important determinants of pro-social behavior. Schwartz (1977) conceptualized personal norms as internalized values and norms which are activated when another person's need is recognized. Hence, personal norms are self-expectations regarding appropriate behavior that an individual constructs in particular situations. This appropriate behavior is motivated by the desire to act in ways which are consistent with the personal value system, regardless of external reinforcement (Schwartz, 1977). Activated personal norms are experienced as feelings of moral obligation to behave in a way that is conform to the self-concept, resulting in favorable self-evaluations. As a consequence, the concept of obligation has been used to operationalize 
personal norms, as it "refers to action" and is "felt directly prior to behavior, whereas reactions such as guilt and pride are responses to action and can only be anticipated" (Schwartz 1977, p. 239). Obligation “energizes” altruistic actions (Schwartz, 1977, p. 231), and is therefore another key determinant of pro-social behaviors.

\section{Personal Norms in Virtual Communities}

Previous research has indicated that members of virtual communities invest time and effort in caring for the community and helping others because they feel that "it is the right thing to do" (McLure Wasko \& Faraj, 2000, p. 168). They did not only help in order to conform to the social norms governing the community, but also to satisfy an internal obligation. Thus, not only reciprocity, but also obligation will take a central place in the framework proposed to explain pro-social behaviors of virtual communities members, as will be discussed in the next section.

\section{Hypotheses}

\section{Main Effects}

There has been considerable debate about the validity of the traditional theory of norms in the online environment. Several scholars purport that the lack of informational cues caused by the text-centered interactions in virtual communities and the associated 'disembodiment' of online individuals may cause conditions that reduce the impact of social norms and promote less socially oriented behaviors (Kiesler \& Sproull, 1992; Johnson, 2001; Bernard, 2002). Another stream of research, on the other hand, stresses the importance of norms in the context of virtual communities (McLure Wasko \& Faraj, 2000; Mathwick, 2002; Von Krogh, 2002). In order to shed light on this controversial issue, we investigate the impact of norms on the pro-social behaviors that are needed to ensure the success and sustainability 
of a virtual community. More specifically, we argue that the norms governing the pro-social behavior of community members intensify in proportion to the value of the informational and socio-emotional benefits received.

It has been well documented that social norms form the basis of personal norms. As stated by Gouldner (1960) and Schwartz (1977), the internalization of the norm of reciprocity morally obliges a person to give back benefits received from another party. In a virtual community, members spend time and effort to communicate with other members by posting messages on the forums or bulletin boards and participating in chat events. Often, members respond to specific requests for information, help, or support, even though they do not receive direct economic benefits in return. Rather, they display these altruistic behaviors because they have been helped by the community before and feel that they have to "give back in return" (McLure Wasko \& Faraj, 2000, p. 169). This desire for reciprocity generates an obligatory impetus to actively care for the community. Therefore, we propose that also in the context of virtual communities, reciprocity leads to direct feelings of obligation.

\section{H1: Reciprocity has a positive impact on obligation.}

The initial motivational factor underlying the participation in a virtual community is the access to content generated by the members: the informational and socio-emotional value that members expect to receive from the community. In line with Babin, Darden, and Griffin (1994), we define value in very broad terms as all objective and subjective criteria that make up the entire experience in the community. Rheingold (1993, p. 6) states that "the exchange of information and the sharing of emotional sympathy" are the main reasons for joining a community. Intuitively, the gathering of information, which is central to a consumer's interest, is a strong motivator to participate in a community. Research has shown that a large 
percentage of consumers join a virtual community because they want to receive informational support (Burnett, 2000) and engage in the exchange of ideas and solutions. However, "communities are not developed by forming relationships with information, but with people," as Clark (2000, p. 143) states. Hence, another important aspect why people choose to join a virtual community is the socio-emotional value it provides. Even in communities that focus on purely technical or informational issues and are not explicitly designed as social support groups, the development of interpersonal relationships and social exchange is common. In the online technical support communities of Hewlett Packard for example, most of the discussion focuses on highly specific technical details, but also entire threads containing only social exchanges can be found (such as system administer jokes, bets on formula 1 races, etc.). Furthermore, Muniz and O'Guinn (2001) anticipated that the resources shared in a community would include both informational and emotional support, and Burnett (2000) notes that virtual communities clearly function as forums for both informational and socioemotional exchanges. Finally, McAlexander, Schouten, and Koenig (2002) state that a community benefits from the reciprocal exchanges of value. As both informational and socioemotional value are created in a social space, we expect that the consumption of this value will intensify the social norm (Schwartz, 1977). It is important to note that even though the social norm of reciprocity is universal (i.e. prevalent in all groups to which an individual belongs), it is not unconditional (Gouldner, 1960). Rather, the intensity of the norm is "contingent upon the imputed value of the benefit previously received" (Gouldner, 1960, p. 171), which in our case is the value of the informational and socio-emotional support provided by the community. Consequently, we propose that both the informational and socioemotional value have a positive impact on reciprocity.

H2: Perceived informational value has a positive impact on reciprocity. 
H3: Perceived socio-emotional value has a positive impact on reciprocity.

As previously discussed, reciprocity and obligation are two well-documented antecedents of pro-social behavior. Pro-social behavior in our virtual community setting is conceptualized by two constructs: community citizenship behavior and contribution intentions. Community citizenship behavior is based on the conception of the term "organizational citizenship behavior", which is defined as "behavior(s) of a discretionary nature that are not part of the employee's formal role requirements, but nevertheless promote the effective functioning of the organization" (Organ, 1988, p. 4). This concept can be easily translated into the context of virtual communities, as it "presents the glue which holds collective endeavors together" (Brief \& Motowidlo, 1986, p. 712), which is equally true for both organizations and communities. Furthermore, as virtual community members assume the role of "partial employees" by taking over service functions themselves, citizenship behaviors that have been observed among employees of an organization are expected to be existent among community members as well. As proposed by LePine, Erez, and Johnson (2002), we treat community citizenship behavior as an aggregate construct that encompasses three underlying dimensions: helping ("those voluntary actions that help another person with a problem"), civic virtue ("behavior indicating that a person responsibly participates in and is concerned about the life of the community") and sportsmanship ("the willingness to tolerate less than ideal circumstance without complaining”) (Podsakoff, Ahearne, \& McKenzie, 1997, p. 263). Shared codes of behavior such as community citizenship behavior "lubricate the social machinery" (Smith, Organ, \& Near, 1983, p. 655) and thus contribute to the functioning of a virtual community. Therefore, we propose that members who feel a sense of reciprocity and obligation will behave pro-socially - like responsible community citizens. 
H4: Reciprocity has a positive impact on community citizenship behavior.

H5: Obligation has a positive impact on community citizenship behavior.

Finally, the survival of a virtual community depends on the intentions of the community members to continue their active membership in the future. The virtual community can only succeed if a certain level of sustained interaction is guaranteed (Jones, 1997), ensuring the continuity of the community discussions. Therefore, the intention to provide contributions to the community, much like the intention to exert considerable effort on behalf of an organization (Brief \& Motowidlo, 1986), is another type of pro-social behavior. In a study of the behavior of university alumni, Diamond and Kashyap (1997) confirm that reciprocity and obligation result in the "intention to attend reunions in the future" and the "intention to contribute", which is comparable to intentions to continue the active membership in a virtual community. We therefore expect that feelings of reciprocity and obligation will result in the intentions of members to continue to contribute to their virtual community (de Ruyter \& Wetzels, 2000).

H6: Reciprocity has a positive influence on contribution intentions.

H7: Obligation has a positive influence on contribution intentions.

\section{Moderator Effects}

The relationship between norms and pro-social behavioral intentions is somewhat more complex (Schwartz, 1977; Osterhus, 1997; de Ruyter and Wetzels, 2000). Schwartz (1977) contends that the strength of this relationship is influenced by the presence of certain conditions that are conducive to the activation of social and personal norms. The occurrence of such norm-activating conditions is likely to be determined by the influence of moderating 
variables. These may impact the strength of the relationship between norms and pro-social behavior, making norms a more or less powerful predictor of behavior (Osterhus, 1997). Schwartz (1977) proposes that the norm-behavior link is often influenced by personality moderators (e.g. differences in personality tendencies). Likewise, Ostrom (2000) argues that the development of a theory of collective knowledge sharing must take into account personality traits.

As the essence of virtual communities has been described as a consciousness of joint interaction (Orr, 1990), an important condition for the activation of norms is the inclination of members to communicate with other members. More particularly, members of a social group, such as a virtual community, can only become aware of the rules and guidelines that govern the group through the process of interacting with each other. Von Krogh (2002, p. 97) argues that as people start to interact more closely through electronic media, the reflection on social and personal norms results in "reciprocal relationships in which they exchange small favors and gifts, and perhaps decide on time, place and contents for further exchange". Osterloh and Frey (2000) state that the intrinsic motivation to share knowledge, rooted in the actual activity of interacting online itself, contributes to the realization of behavior conforming to norms. As a result, the frequency of interaction in the virtual community contributes to a condition that is conducive to the activation of social and personal norms. Based on the interaction frequency, Hammond (2000) distinguishes between two types of membership in virtual communities: communicative membership, in which individuals interact frequently, articulate concerns, and respond to messages; and quiet membership, in which individuals read messages but rarely send/post messages of their own (Hammond, 2000; Okleshen \& Grossbart, 1998; Mathwick, 2002). The type of membership that an individual displays is strongly influenced by a certain personality trait, namely his/her general proneness to interact online with others. We expect that members who are more prone to interact online will respond to messages and post 
questions more frequently than the quiet members. As the communicative members engage more in community discussions and actively contribute to the generation of content, they become more aware of the social and personal norms that govern the community, making norms a more powerful predictor of behavior. As a result, they are subject to more normative pressures than members who primarily take on an observing role. Therefore, we will also investigate whether online interaction proneness might have a moderating effect on the relationships between social and personal norms and pro-social behavioral intentions:

H8a: The relationship between reciprocity and community citizenship behavior will be moderated by online interaction proneness.

H8b: The relationship between obligation and community citizenship behavior will be moderated by online interaction proneness.

H9a: The relationship between reciprocity and contribution intentions will be moderated by online interaction proneness.

H9b: The relationship between obligation and contribution intentions will be moderated by online interaction proneness.

The figure below depicts our conceptual model and provides a summary of the hypotheses.

[PLEASE INSERT FIGURE 1 HERE]

\section{Methodology}

\section{Research Setting}

In order to test the aforementioned hypotheses, we conducted a quantitative study among the members of a virtual community of practice for healthcare professionals. This 
community is hosted and moderated by a professional virtual community provider on behalf of an alliance of major suppliers of products and services in the healthcare industry. There are several reasons underlying our choice for this specific community setting. First of all, this virtual community clearly pursues a commercial purpose, as its members are customers of the companies that sponsor the community and have a shared central interest in a commercial activity, namely their profession. The community members range from medical students, nurses, and elderly care nurses to doctors and professors, thus representing a very diverse target audience in terms of knowledge and/or technological sophistication. Furthermore, rapid diffusion of information is vital in the healthcare industry in order to ensure the best treatment of the patients. As information in books and journals is always published with a time lag, healthcare professionals which are in urgent need for up-to-date information are more inclined to turn to the Internet in general and to virtual communities in particular. Consequently, the virtual community under study is continuously updated and modified by the community provider and the members, and characterized by vivid discussions in the forums and chats. Finally, we chose to investigate this particular community setting because the healthcare industry distinguishes itself not only through a strong information need, but also through a high emotional pressure with which the professionals often have to deal. As a result, the topics discussed by the community members are clearly two-fold. Frequently, the discussions focus on pure information exchange; the members exchange for example experiences about certain treatment methods and medications. On the other hand, the members also often address more personal issues, such as frustrations with the administration of hospitals and health insurances, or concerns about the destiny of a patient. The virtual community was launched in 1996 and is one of the world's largest information sources concerning healthcare on the Internet. Its mission is to be the meeting place for professionals to collaborate peer-topeer, enabling the exchange of best practices and ideas. In addition to an extensive library of 
specialized articles, a product center, FAQs, and information on events and news, the community also provides the professionals with a place where they can interact with each other and with weekly featured experts via email, message boards, discussion forums and chat. The community members do not only share knowledge by posting messages, but they are also encouraged to provide literature and links to other relevant information sources, which are then incorporated into the community libraries. As the community does not require formal subscription, it is not possible to state the exact number of members. Nevertheless, the average amount of page views per week during the time of our data collection approximately between 1700 and 1800 - gives an indication of the membership size of the virtual community (even though we have to take into account that the active members will visit the community site several times per week).

\section{Questionnaire Development}

Each construct in the model is measured using a multiple-item measurement scale. All measures use a 5-point Likert type response format, with "strongly disagree" and "strongly agree" as the anchors. We mainly used (sub)scales that have been validated by empirical research. Items were selected and adapted to the specific characteristics of our research setting on the basis of interviews with 20 virtual community members and 7 virtual community managers. In the pretest, the preliminary questionnaire - consisting of 36 items - was completed by 85 community members and then subjected to reliability and exploratory factor analysis. Due to low reliability scores or cross-loadings, 7 items were eliminated from the questionnaire, resulting in a final list of 29 items.

Perceived informational value is measured by four items that were taken from Okleshen and Grossbart (1998), while socio-emotional value consists of three items adapted from McLure Wasko and Faraj (2000). To measure online interaction proneness, we 
developed three items specifically for this study. Reciprocity and obligation both consist of a four-item scale which we adapted from de Ruyter and Wetzels (2000) and McLure Wasko and Faraj (2000). To measure contribution intentions, we used a 4-item scale based on Garbarino and Johnson (1999). Furthermore, community citizenship behavior consists of three subscales. Helping is measured with three, civic virtue and sportsmanship with two items respectively, each adapted and adjusted from Podsakoff, Ahearne and McKenzie (1997). In addition, two background variables, namely nationality and gender, were added. Finally, the online questionnaire also provided information on the date of completion and the remote user name, ensuring that each respondent could fill out the questionnaire only once. A list of the questionnaire items is included in table 2.

\section{Data Collection}

Due to the anonymity of the virtual community members, the data was collected via a three-page online questionnaire that was linked to a pop-up screen on the home page of the virtual community. The pop-up screen, which featured the logo of both the university and the community provider, explained the rationale of the study and invited the members to participate by clicking on the provided link. In total, 272 questionnaires were completed, but after elimination of questionnaires from which excessive amounts of data were missing, the final sample consisted of 239 respondents. As we do not know how many community members have seen the pop-up screen featuring our survey, but decided not to respond, we cannot estimate a precise response rate. Furthermore, we do not have information about the non-respondents, again due to the anonymity of the community members. To overcome this problem, we carried out a time trend extrapolation test. The assumption of such a test is that respondents who respond less readily are similar to non-respondents (Armstrong \& Overton, 1977). Only a negligible number of variables (less than 3\%) used in the questionnaire showed

a significant difference between early and late respondents. However, this number of 
variables was distributed among all items of the questionnaire and no consistent pattern could be discerned. Therefore, we may conclude that our data set did not exhibit response-related problems.

\section{Measurement Properties}

To examine the critical measurement issues of the scales used in our research, we conducted a confirmatory factor analysis. As the number of items adversely affects the acceptance of structural equation models (Bentler \& Chou, 1987), we split the scales used in our study into three subsets (cf. Kumar, Stern, \& Achrol, 1992). The first model includes information value, socio-emotional value, and online interaction proneness. The second model consists of reciprocity, obligation, and contribution intentions. The third model includes the three subscales of community citizenship behavior; namely helping behavior, civic virtue, and sportsmanship. The first two models were estimated as conventional firstorder factor models, whereas the third model was estimated as a second-order factor model.

The first measurement property that we examined was the unidimensionality of the scales. The goodness-of-fit statistics of the three models provided us with the necessary information to determine whether a scale is unidimensional (Steenkamp \& Van Trijp, 1990). In assessing the unidimensionality of the scales, we were confronted with scale items that "misbehaved". In order to preserve scale purity, we decided to disregard these items (cf. Anderson \& Gerbing, 1988). In the final version of the questionnaire, the following three

items were deleted: (1) 'I am someone who usually rather observes than participates in discussion forums (online interaction proneness), (2) 'I owe a lot to the X community' (reciprocity), and (3) 'I think the X community should be able to count on my support' (obligation). The goodness of fit statistics for each for the three models is summarized below in table 1. 


\section{[PLEASE INSERT TABLE 1 HERE]}

As for each of the three models the values for the goodness-of-fit indices are above their suggested cut-off values (Hu \& Bentler, 1999; Bollen, 1989), we can state that the focal scales of our research are unidimensional.

The reliability of the scales was assessed using Jöreskog's (1971) measure of composite reliability. From the results of our reliability analysis, which are presented in table 2, we can conclude that our scales are indeed reliable. Within-method convergent validity is supported by the fact that most items loaded higher than 0.50 on their respective construct and all the t-values that are significant at the .05 level.

For the first two models, discriminant validity was evaluated in the following three ways. First, we performed chi-square difference tests. Second, we conducted Fornell and Larcker's (1981) test of average variance extracted. Third, we established 99\%-confidence intervals of the correlation coefficients among the various constructs. All three methods were unanimous in their conclusion that discriminant validity was present. Table 2 provides an overview of the results of our CFA.

[PLEASE INSERT TABLE 2 HERE]

\section{Data Analysis and Results}

\section{Testing for Main Effects}

In order to test our hypotheses, we specified and estimated the following system of equations: 


$$
\begin{aligned}
& R E C=\alpha_{1}+\beta_{1} I N F O+\beta_{2} E M O+\varepsilon_{1} \\
& O B L=\alpha_{2}+\beta_{3} R E C+\varepsilon_{2} \\
& C C B=\alpha_{3}+\beta_{4} R E C+\beta_{5} O B L+\varepsilon_{3} \\
& C O N T=\alpha_{4}+\beta_{6} R E C+\beta_{7} O B L+\varepsilon_{4}
\end{aligned}
$$

$$
\text { Where: } \begin{array}{rlll}
\text { REC } & =\text { Reciprocity } & O B L & =\text { Obligation } \\
\text { INFO } & =\text { Informational value } & C C B & =\text { Community citizenship behavior } \\
\text { EMO } & =\text { Socio-emotional value } & C O N T=\text { Contribution intentions }
\end{array}
$$

In determining the optimal estimation procedure for the above-presented system of equations, we had to take several considerations into account. First of all, as this system of linear regression equations is fully recursive and identified, we considered estimating each equation separately. However, the results of a Breusch-Pagan test (Breusch \& Pagan, 1980) indicated that there is significant contemporaneous correlation among the error terms across the equations and that the endogenous variables are not stochastically independent of all error terms. Therefore, the use of ordinary least squares to estimate the separate equations may lead to biased and inconsistent results. In order to overcome these limitations and to have valid tests of the hypotheses, it is necessary to employ a simultaneous equation modeling technique (c.f. Ramanathan, 1998). Due to the exploratory nature of our study and our focus on theory development, a parameter-oriented methodology like maximum likelihood estimation (e.g. LISREL), which is more suited for theory testing, is not the ideal approach to our analysis (Fornell \& Cha, 1994). Rather, we chose for a method that ensures optimal prediction accuracy. Therefore, we opted for Zellner's seemingly unrelated regression (SUR) approach (Dufour \& Khalaf, 2002; Zellner, 1962), which is a prediction-oriented methodology that aims to maximize the proportion of explained variance and accounts for intercorrelations among the various equations specified above. The term 'seemingly unrelated regression' is used to reflect the fact that, even though superficially they do not seem to be linked, the 
individual equations are in fact statistically related to each other (Kontoghiorghes \& Clarke, 1995). The results for the total sample are summarized below in table 3.

\section{[PLEASE INSERT TABLE 3 HERE]}

As all F-values are significant at the .01 level, we may conclude that our model fits adequately to the data (system weighted $\mathrm{R}^{2}=.60$ ). The significance tests for the seemingly unrelated regression parameters are the basis for accepting or rejecting our hypotheses. Feelings of obligation are positively and significantly influenced by reciprocity (coefficient $=$ 1.03, t-value $=18.07)$, supporting Hypothesis 1. A significant positive relationship is also found between both informational value and reciprocity $($ coefficient $=.40, \mathrm{t}$-value $=6.22)$ and socio-emotional value and reciprocity (coefficient $=.28, \mathrm{t}$-value $=5.23)$. We therefore fail to reject Hypotheses 2 and 3. Community citizenship behavior is significantly influenced by both reciprocity $($ coefficient $=.39, \mathrm{t}$-value $=7.51)$ and obligation $($ coefficient $=.33, \mathrm{t}$-value $=$ 7.83), supporting Hypotheses 4 and 5. Finally, our study also supports Hypotheses 6 and 7. Our results corroborate a positive significant relationship between reciprocity and contribution intentions (coefficient $=.60 ; \mathrm{t}$-value $=8.60$ ) and obligation and contribution intentions $($ coefficient $=.31 ; \mathrm{t}$-value $=5.39)$. Figure 2 summarizes our results.

\section{[PLEASE INSERT FIGURE 2 HERE]}

The hypotheses concerning the possible moderating effect of online interaction proneness will be discussed in the next section. 


\section{Testing for Moderator Effects}

Additionally, we were interested in examining whether the relationships between social and personal norms and pro-social behavioral intentions are moderated by the degree of online interaction proneness of the individual community members. To examine the presence of moderator effects, we performed a moderated regression analysis (MRA), again using the SUR approach. For this purpose, we extend the equations in our system by adding a qualitative variable and interaction terms, as shown below:

$$
\begin{aligned}
& R E C=\pi_{1}+\gamma_{1} I N F O+\gamma_{2} E M O+\lambda_{1} I P+\lambda_{2}\left(I N F O^{*} I P\right)+\lambda_{3}\left(E M O^{*} I P\right)+\varepsilon_{5} \\
& O B L=\pi_{2}+\gamma_{3} R E C+\lambda_{4} I P+\lambda_{5}\left(R E C^{*} I P\right)+\varepsilon_{6} \\
& C C B=\pi_{3}+\gamma_{4} R E C+\gamma_{5} O B L+\lambda_{6} I P+\lambda_{7}\left(R E C^{*} I P\right)+\lambda_{8}\left(O B L^{*} I P\right)+\varepsilon_{7} \\
& C O N T=\pi_{4}+\gamma_{6} R E C+\gamma_{7} O B L+\lambda_{9} I P+\lambda_{10}\left(R E C^{*} I P\right)+\lambda_{11}\left(O B L^{*} I P\right)+\varepsilon_{8}
\end{aligned}
$$

Where: $\begin{array}{llll}\text { REC } & =\text { Reciprocity } & O B L=\text { Obligation } \\ \text { INFO } & \text { Informational value } & C C B=\text { Community citizenship behavior } \\ E M O= & \text { Socio-emotional value } & C O N T=\text { Contribution intentions } \\ I P & =\begin{array}{l}\text { Online interaction } \\ \text { proneness dummy }\end{array} & & \end{array}$

Even though the analysis of interaction effects has the potential to provide valuable additional insights, it is often very difficult to interpret (Aiken \& West, 1991). In order to decrease the difficulty of interpretation, we decided to transform the continuous variable online interaction proneness into a qualitative variable. The formation of this qualitative variable used in the MRA was based on a median split procedure. Furthermore, this qualitative variable was defined by means of contrast coding, in order to obtain orthogonality among the various categories. We used centered data to estimate the MRA model in order to avoid problems due to multicollinearity (cf. Cronbach, 1987).

To determine how online interaction proneness might moderate the relationships specified in our model, we used the sequence of steps suggested by Kleinbaum, Kupper, Muller, and Nizam (1998). First of all, a coincidence test was performed. In case of a 
significant F-value for the coincidence test, we proceeded by performing follow-up tests to test for parallelism and equal elevation of the relationships. The results of the Kleinbaum et al. (1998) procedure are presented below in table 4.

\section{[PLEASE INSERT TABLE 4 HERE]}

Based on the results in table 4, we can conclude that online interaction proneness significantly moderates three out of four relationships specified in our model (see column 'coincidence'). To get a more exact picture of the nature of the moderating effect of online interaction proneness, the results for the parallelism and equal elevation tests are pivotal. Regarding the test for equal elevation, we see that the intercept for equations (5) and (6) are significantly higher for the high online interaction proneness group $\left(\lambda_{1}=.16(\mathrm{t}\right.$-value $=2.98)$; $\lambda_{2}=.10(\mathrm{t}$-value $\left.=1.68)\right)$. This means that under a ceteris paribus condition, community members with a high degree of online interaction proneness exhibit a higher degree of reciprocity and obligation respectively than the community members which are less prone to interact online.

Concerning the test for parallelism, we can state that for equation (8), the impact of obligation and reciprocity on contribution intentions is modified by the degree of online interaction proneness, supporting hypotheses $9 \mathrm{a}$ and $9 \mathrm{~b}$. Based on the results in table 4 , we can conclude that for community members characterized by a high degree of online interaction proneness, both reciprocity $\left(\lambda_{10}=.14(\mathrm{t}\right.$-value $\left.=2.34)\right)$ and obligation $\left(\lambda_{11}=.18(\mathrm{t}-\right.$ value $=2.63))$ have a significantly higher impact on the formation of contribution intentions than for community members that exhibit a lower degree of online interaction proneness. Hypotheses $8 \mathrm{a}$ and $8 \mathrm{~b}$ could not be supported, on the other hand. No matter whether a 
community member is more or less prone to interact online, the relationships between reciprocity and obligation and community citizenship behavior remain equally strong.

\section{Conclusions}

\section{Discussion}

The potential to reconcile economic benefits to the company with the social needs of customers has made commercial virtual communities a popular tool for companies to add a valuable interactive service option to their traditional service offering. Essentially, the success of each virtual community depends on the behavior of the community members. Meaningful content will only be created and relationships will only be forged in virtual communities in which the members care for and actively participate in the community on a continuous basis.

Therefore, in this paper, we investigated the role of social and personal norms in relation to the pro-social behaviors (citizenship behavior and contribution intentions) that the members have to exhibit in order to keep their virtual community active and alive. Our results show that the two primary resources which are exchanged in the social space of a virtual community - namely informational value and socio-emotional value - intensify the social norm of reciprocity felt by community members. Furthermore, we find a very strong positive relationship between the reciprocity and the personal norm of obligation. Thus, as expected, the social norm is internalized and leads to the formation of a personal norm, which in our case means that the sense of reciprocity is translated into feelings of obligation. Finally, both the norm of reciprocity and feelings of obligation have a significant impact on the pro-social behavioral intentions included in our framework, namely community citizenship behavior and contribution intentions.

According to our findings, the theory of norms known from traditional face-to-face communities also plays a vital role in governing the behavior of individuals in virtual 
communities. Apparently, members who have found support in the virtual community, such as the answer to a specific information need, or just the empathy of another community member in an emotionally difficult situation, feel a sense of indebtness to the entire community. Consequently, the member who has been helped wants to reciprocate the favor and feels obliged to take the effort to answer to someone else's posted problem the next time, even though this action will not provide him/her with any direct economic benefits. In general, the social and personal norms activated during the community discussions elicit community citizenship behaviors from the members: they will try to help others, actively participate in the community 'life', and tolerate minor imperfections in the community. Furthermore, when the members receive the informational and/or socio-emotional support that they seek in the virtual community, they will have the feeling that they 'owe to the community' and that they have to 'stick around' in case their help is needed, resulting in continued membership. Our results are in line with those of other researchers (Constant, Sproull, \& Kiesler, 1996; McLure Wasko \& Faraj, 2000), who found that members of virtual communities initially participate in a virtual community because they aspire access to knowledge on a specific topic of interest or access to a specific group of like-minded people, but ultimately become involved and develop the desire to help others out of a sense of moral duty and an interest to advance the community as a whole.

In addition, we were interested in investigating the potential moderator effect of online interaction proneness, a personality trait, on the relationships between social and personal norms and pro-social behavioral intentions. In order to examine possible interaction effects, we transformed the continuous variable online interaction proneness into a qualitative one, consisting of a 'high' and a 'low' online interaction prone group. The analysis showed several interesting results. First of all, the group which is more prone to interact online feels in general a stronger sense of reciprocity and obligation than the group which is less prone to 
interact online. In other words, the members who are more communicative are more willing to reciprocate and return the help that they receive from their fellow members in the community. Furthermore, the positive relationship between both reciprocity and contribution intentions and obligation and contribution intentions is stronger for the group that is more prone to interact online than for the other group. Thus, if the social and personal norms felt by the members become more intense during the course of the membership in the community, both reciprocity and obligation become stronger determinants of the intention to contribute to the community in the future for the communicative members. A potential explanation for this result can be found by making a distinction between the 'process' and the 'outcome' of the virtual community membership. In the services marketing literature, this distinction has been frequently made in judging the quality and the satisfaction with the service delivery process (Ostrom \& Iacobucci, 1995) in contrast to the service outcome (Lytle \& Mokwa, 1992). In this context, the service delivery process has been compared to the implicit benefits of the service, while the service outcome has been associated with the explicit benefits of the service (Lytle \& Mokwa, 1992). In a virtual community, the 'implicit process' refers to the exchange of informational and socio-emotional support by posting and reading messages - the process of content creation. The 'explicit outcome', on the other hand, refers to the information contained in the posts - the outcome is the content itself. The members who are more prone to interact online might put more emphasis on the process of content creation (the process of interacting with others) than on the content (the post) itself. Through their repeated interactions with fellow members, they become more aware of the social and personal norms that govern the interactive behavior in the community. Consequently, the norm of reciprocity and feelings of obligation become stronger determinants of contribution intentions for the communicative members than for the quiet members. 
Finally, it is important to note that online interaction proneness did not have a moderating effect on the relationships between reciprocity and obligation and community citizenship behavior. No matter whether a member is more or less prone to interact online, the strength of the relationships between social and personal norms and community citizenship behaviors remain equally strong. As discussed by many authors, members of virtual communities develop shared codes of behavior which are key to the success and survival of the community (Rheingold, 1993; Hagel \& Armstrong, 1997; Kozinets, 1999; Mathwick, 2002). Even though different member types can be discerned in each community (such as communicative vs. quiet members), these codes of behavior seem to be generalizable to everyone. We therefore conclude that community citizenship behavior, which entails helping behavior, civic virtue, and sportsmanship, seems to be a fundamental determinant of the success of a commercial virtual community.

\section{Limitations and Future Research Guidelines}

The findings of this study should be read with the understanding that limitations exist. In the first place, our framework focuses on the mediating role of social and personal norms in the formation of pro-social behavioral intentions. Clearly, we did not consider all concepts that might be relevant in this context. Future research should be directed at including other aspects of virtual communities, such as satisfaction, trust, commitment and loyalty. We also included only one moderating variable, namely online interaction proneness, in our study. As a suggestion for future research, we recommend to examine the role of other moderating variables as well, such as more personal or situational characteristics. Second, our study assumes that members have a certain perception of the informational and socio-emotional value provided by the virtual community. It would be interesting to study how these perceptions are formed, in other words, what the antecedents of informational and socio- 
emotional value are. Third, our study was conducted in only one specific virtual community, namely a community for healthcare professionals. A prime motivation for these healthcare professionals to participate in the community is the acquisition of information that they need in order to perform their job better. As a result, our findings might place an extraordinary emphasis on informational value, which might not be found in commercial virtual communities that have different objectives. Future research should investigate different virtual community settings in order to see whether similar relationships can be found. Furthermore, due to the anonymity of the members of the virtual community that we investigated, we can only give an approximation of the response rate and cannot make any statements about the characteristics that distinguish respondents from non-respondents. Therefore, our results might be slightly influenced by a self-selection bias, meaning that the members who took the effort to respond to our survey might be more involved with the virtual community and more prone to interact online than the non-respondents (even though the variable online interaction proneness exhibits sufficient variance). Finally, all concepts and relationships were measured at one point in time, thus essentially from a static perspective. It may be worthwhile to study especially the relationships between social and personal norms and pro-social behavioral intentions over time. This consideration is especially important in this study because norms take time to develop during the 'socialization process' of a new member.

\section{Managerial Implications}

The conclusions drawn from this research also hold several interesting implications for companies that want to sponsor a virtual community. Our research has pointed to a number of important determinants of active community participation that can be directly or indirectly influenced by the community sponsor. While social and personal norms, which are the main 
determinants of community citizenship behaviors and contribution intentions, cannot be directly influenced, they are impacted by the value of the information and the socio-emotional support provided in the community. Accordingly, if the perceived value of these two aspects increases, also the feelings of reciprocity and obligation of the members become stronger, ultimately increasing the intentions to perform community citizenship behaviors and to contribute continuously to the virtual community. Thus, a community sponsor should try to stimulate community members to provide valuable information and socio-emotional support. This goal may be achieved, for example, through the introduction of 'point reward systems'. Each community member collects points for each of his/her answers to a previous post, which are awarded by the poster of the original question based on the usefulness of the answer. When a virtual community member has collected a certain amount of points, $\mathrm{s} /$ he receives a certain degree or upgrade (e.g. in the technical support communities of HP, these degrees range from "expert", "wizard" to "olympian"). This degree is visible to all other members and provides a certain amount of status, stimulating others to receive the same kind of degree or to surpass other members (Gatignon \& Robertson, 1986). As a result, such a point system not only stimulates the frequency of interaction, but also the quality of the postings. Another method to make the pro-social behavior aspired from community members more visible and explicit is the establishment of 'netiquette', which is a code of conduct explicitly stating the desired behaviors of community members. If the netiquette of the virtual community is known by every member, the expectations of social norms, and consequently their reinforcement by the group, are stronger. As a result, if reciprocity and obligation are increased, also community citizenship behavior and contribution intentions will be positively affected. An additional implication for the virtual community sponsor regards the moderation of the virtual community. The value of both information and socio-emotional support can be controlled and stimulated through the presence of a moderator who actively engages in the community 
discussions. This moderator can either be a representative of the sponsoring company or an appointed community member. The task of the moderator is to monitor the discussions, order the individual posts according to discussion threads, respond to requests of other members (both regarding information and socio-emotional support), and initiate new 'up-to-date' discussion threads. In such a way, the exchange processes as well as the discussion outcomes in the virtual community can be controlled to a certain extent. To further increase the quality of the informational and socio-emotional exchanges, the sponsoring company can also try to recruit experts for the virtual community, which can be either very knowledgeable clients or other industry experts. If these experts can be convinced to join the virtual community, their contributions will certainly add to and stimulate the community discussions, resulting in higher informational and socio-emotional value for other members. Finally, a company that sponsors a commercial virtual community can try to influence the value that its members perceive in the community by facilitating collective exchanges. The website of the virtual community has to be functional, both in terms of availability and performance, and it has to offer the necessary technical features to enable meaningful interaction. Regular online surveys or interviews with the virtual community members can be an effective tool in order to understand the needs and wishes of the customers with regard to the technical features of the community as well as its management. If the commercial virtual community is to be successful, it is vital that the feedback of the community members is adequately taken into account by the community sponsor. 


\section{References}

Aiken, L. S., \& West, S. G. (1996). Multiple regression. Sage Publications.

Anderson, J. C., \& Gerbing, D. G. (1988, May). Structural equation modeling in practice: a review and recommended two-step approach. Psychological Bulletin, 103, 411-423.

Albrecht, K., \& Zemke, R. (2001). Service America in the new economy. New York: McGraw-Hill.

Armstrong, J. S., \& Overton, T. S. (1977, August). Estimating nonresponse bias in mail surveys. Journal of Marketing Research, 14, 396-402.

Babin, B. J., Darden, W., \& Griffin, M. (1994, March). Work and/or fun: measuring hedonic and utilitarian shopping value. Journal of Consumer Research, 20, pp. 644-654.

Bagozzi, R. P., \& Dholakia, U. M. (2002, spring). Intentional social action in virtual communities. Journal of Interactive Marketing, 16 (2), 2-21.

Balasubramanian, S., \& Mahajan, V. (2001). The economic leverage of the virtual community. International Journal of Electronic Commerce, 5 (3), pp. 103-138.

Bell, C., \& Newby, H. (1974). The sociology of community. London: Frank Cass and Co. Ltd.

Bentler, P. M., \& Chou, C. P. (1987). Practical issues in structural modeling. Sociological Methods and Research, 16, 78-117.

Bernard, M. (2002). The effect of altering levels of groupness on group process and performance outcomes in computer-mediated interactions, retrieved August 20, 2002, from http://psychology.wichita.edu/hci/projects/GroupProcessStudy\%5B1\%5D.PDF.

Bollen, K. A. (1989). Structural equations with latent variables. New York: Wiley.

Bressler, S .E., \& Grantham, C. E. (2000). Communities of commerce. San Francisco: McGraw-Hill.

Breusch, T. S., \& Pagan, A. R. (1980). The Lagrange multiplier test and its applications to model specification in econometrics. Review of Economic Studies, 18, 239-253. 
Brief, A. P., \& Motowidlo, S. J. (1986). Pro-social organizational behaviors. Academy of Management Review, 11, 710-725.

Burnett, G. (2000). Information exchange in virtual communities: a typology. Information Research, 5 (4).

Clark, N. (2000). Education, communication, and consumptions: piping in the academic community. In: C. Werry, \& M. Mowbray (Eds.), Online communities, commerce community action, and the virtual university (pp. 129-151). Hewlett Packard Company, New York: Prentice Hall.

Cialdini, R. B., Kallgren, C. A., \& Reno, R. R. (1991). A focus theory of normative conduct: a theoretical refinement and reevaluation of the role of norms in human behavior. In: L. Berkowitz (Ed.), Advances in Experimental Social Psychology (pp. 201-214). New York: Academic Press.

Constant, D., Sproull, L., \& Kiesler, S. (1996, March-April). The kindness of strangers: the usefulness of electronic weak ties for technical advice. Organizations Science, 7 (2), 119135.

Cothrel, J., \& Williams, R. L. (1999). On-line communities: helping them form and grow. Journal of Knowledge Management, 3 (1), 54-60.

Cronbach, L. (1987). Statistical tests for moderator variables: flaws in analysis recently proposed. Psychological Bulletin, 102, pp. 414-417.

de Ruyter, J. C., \& Wetzels M. G. M. (2000). With a little help from my fans - extending models of pro-social behaviour to explain supporters' intentions to buy soccer club shares. Journal of Economic Psychology, 21, 387-409.

Diamond, W. D., \& Kashyap, R. K. (1997). Extending models of pro-social behavior to explain university alumni contributions. Journal of Applied Social Psychology, 27 (10), 915-928. 
Dufour, J. M., \& Khalaf, L. (2002). Exact tests for contemporaneous correlation of disturbances in seemingly unrelated regressions. Journal of Econometrics, 106, 143-170.

Etzioni, A., \& Etzioni, O. (1999). Face-to-face and computer-mediated communities, a comparative analysis. The Information Society, 15, 241-248.

Feldman, D. C. (1984, January). The development and enforcement of group norms. Academy of Management Review, 9, 47-53.

Fernback, J., \& Thompson, B. (1995). Virtual communities: abort, retry, failure? Available from http://www.well.com/user/hlr/texts/Vccivil.html.

Fischer, E., Bristor, J., \& Gainer, B. (1996). Creating or escaping community? An exploratory study of internet consumers' behaviors. Advances in Consumer Research, 23, 178-182.

Fisher, R. J., \& Ackerman, D. (1998, December). The effects of recognition and group need on volunteerism: a social norm perspective. Journal of Consumer Research, 25, 262-275.

Fornell, C., \& Cha, J. (1994). Partial least squares. In R. P. Bagozzi (Ed.). Advanced methods of marketing research (pp. 52-78). Cambridge: Blackwell.

Fornell, C., \& Larcker, D. F. (1981). Evaluating structural equation models with unobservable variables and measurement error. Journal of Marketing Research, 18, 19-50.

Fowler, R. B. (1991) The dance with community: the contemporary debate in American political thought. Lawrence, KS: University of Kansas Press.

Garbarino, E., \& Johnson, M. S. (1999, April). The different roles of satisfaction, trust, and commitment in customer relationships. Journal of Marketing, 63, 70-87.

Gatignon, H., \& Robertson, T. S. (1986). An exchange theory model of interpersonal communication. Advances in Consumer Research, 13 (1), 534-538.

Gouldner, A. W. (1960). The norm of reciprocity. American Sociological Review, 25, 165178. 
Hagel, J., \& Armstrong A. (1997). Net gain: expanding markets through virtual communities. Boston, MA: Harvard Business School Press.

Hammond, M. (2000). Communication within on-line forums: the opportunities, the constraints and the value of a communicative approach. Computers \& Education, 35, 251262.

Hillery, G. A. (1955). Definitions of community: areas of agreement. Rural Sociology, 2, 111 123.

Hu, L., \& Bentler P. M. (1999). Cutoff criteria for fit indices in covariance structures analysis: conventional criteria versus new alternatives. Structural Equation Modeling, 6 (1), pp. 1-55.

Johnson, C. M. (2001). A survey of current research on online communities of practice. Internet and Higher Education, 4, 45-60.

Jones, Q. (1997). Virtual communities, virtual settlements \& cyber-archaeology: a theoretical outline. Journal of Computer-Mediated Communication, 3 (3). Available from http://www.ascusc.org/jemc/vol3/issue3/jones.html.

Joereskog, K. G. (1971). Statistical analysis of sets of congeneric tests. Psychometrika, 36, $109-133$

Kiesler, S., \& Sproull, L. (1992). Group decision making and technology. Organizational Behavior and Human Decision Processes, 52, 93-123.

Kleinbaum, D. G., Kupper, L. L., Muller, K. E., \& Nizam, A. (1998). Applied regression analysis and other multivariable methods. $3^{\text {rd }}$ edition. Pacific Grove: Duxbury Press.

Kontoghiorghes, E. J., \& Clarke, M. R. B. (1995). An alternative approach for the numerical solution of seemingly unrelated regression equations models. Computational Statistics \& Data Analysis, 19, 369-377. 
Kozinets, R. V. (1999). E-tribalized marketing?: the strategic implications of virtual communities of consumption. European Management Journal, 17 (3), 252-264.

Kozinets, R. V. (2002, February). The field behind the screen: using netnography for marketing research in online communities. Journal of Marketing Research, 39, 61-72.

Kumar, N., Stern, L. W., \& Achrol, R. S. (1992, May). Assessing reseller performance from the perspective of the supplier. Journal of Marketing Research, 20, pp. 238-253.

LePine, J. A., Erez, A., \& Johnson, D. E. (2002). The nature and dimensionality of organizational citizenship behavior: a critical review and meta-analysis. Journal of Applied Psychology, 87 (1), pp. 52-65.

Lytle, R. S., \& Mokwa, M. P. (1992). Evaluating health care quality: the moderating role of outcomes. Journal of Health Care Marketing, 12 (1), pp. 4-14.

Mathwick, C., Malhotra, N., \& E. Rigdon, E. (2001). Experiential value: conceptualization, measurement and application in the catalog and Internet shopping environment. Journal of Retailing, 77, 39-56.

Mathwick, C. (2002, winter). Understanding the online consumer: a typology of online relational norms and behavior. Journal of Interactive Marketing, 16 (1), 40-55.

McAlexander, J. H., Schouten, J. W., \& Koenig, H. F. (2002, January). Building brand community. Journal of Marketing, 66, 38-54.

McLure Wasko, M., \& Faraj, S. (2000). It is what one does: why people participate and help others in electronic communities of practice. Journal of Strategic Information Systems, 9, $155-173$

McWilliam, G. (2000, spring). Building stronger brands through online communities. Sloan Management Review, 43-53.

Miniard, P. W., \& Cohen, J. B. (1983). Modeling personal normative influences on consumer behavior. Journal of Consumer Research, 10, 169-180. 
Muniz, A. M., \& O’Guinn, T. (2001, March). Brand community. Journal of Consumer Research, 27, 412-432.

Naisbitt, J., Naisbitt, N., \& Philips, D. (2001). High tech, hight touch: technology and our accelerated search for meaning. Napervielle, IL: Nicholas Brealey Publishing.

Okleshen, C., \& Grossbart, S. (1998). Usenet groups, virtual community and consumer behaviors. Advances in Consumer Research, 25, 276-282.

Organ, D. W. (1988). Organizational citizenship behavior: the good soldier syndrome. Lexington, MA: Lexington Books.

Orr, J. (1990). Sharing knowledge, celebrating identity. War stories and community memory in a service culture. In D. Middletin, \& D. Edwards (Eds.), Collective remembering: memory in society (pp. 169-189). London: Sage.

Osterhus, T. L. (1997). Pro-social consumer influence strategies: when and how do they work? Journal of Marketing, 61, 16-29.

Osterloh, M., \& Frey, B. (2000). Motivation, knowledge transfer, and organizational forms. Organization Science, 11 (5), pp. 538-550.

Ostrom, A., \& Iacobucci, D. (1995, January). Consumer trade-offs and the evaluation of services. Journal of Marketing, 59, pp. 17-28.

Ostrom, E. (2000). Crowding out citizenship. Scandinavian Political Studies, 23 (11), pp. 316.

Podsakoff, P. M., Ahearne, M., \& McKenzie, S. B. (1994). Organizational citizenship behavior and the quantity and quality of work group performance. Journal of Applied Psychology, 82 (2), 262-270.

Price, L. L., Feick, L. F., \& Guskey, A. (1995). Everyday market helping behavior. Journal of Public Policy and Marketing, 14, 255-266. 
Puddifoot, J. E. (1995). Dimensions of community identity. Journal of Community \& Applied Social Psychology, 5, 357-370.

Puffer, S. M. (1987). Prosocial behavior, noncompliant behavior, and work performance among commission salespeople. Journal of Applied Psychology, 72 (4), 615-621.

Ramanathan, R. (1998). Introductory econometrics with applications. Dryden Press.

Rheingold, H. (1993). The virtual community: homesteading on the electronic frontier. MA: Addison-Wesley.

Rothaermel, F., \& Sugiyama, S. (2001). Virtual internet communities and commercial success: individual and community-level theory grounded in the atypical case of TimeZone.com. Journal of Management, 27, 297-312.

Schwartz, S. H. (1977). Normative influences on altruism. Advances in Experimental Social Psychology, 10, 222-280.

Smith, C. A., Organ, D. W., \& Near, J. P. (1983). Organizational citizenship behavior: Its nature and antecedents. Journal of Applied Psychology, 68 (4), 653-663.

Steenkamp, J. B. E. M., \& van Trijp, H. C. M. (1991). The use of LISREL in validating marketing constructs. International Journal of Research in Marketing, 8 (4), 283-299).

Toennies, F. (1912). Gemeinschaft und Gesellschaft: Grundbegriffe der reinen Soziologie [Community and society: key terms of the pure sociology]. $2^{\text {nd }}$ edition, Berlin: Curius (in German).

von Krogh, G. (2002). The communal resource information systems. Journal of Strategic Information Systems, 11, pp. 85-107.

Zellner, A. (1962). An efficient method for estimating seemingly unrelated regressions and tests for aggregate bias. Journal of the American Statistical Association, 57, 348-368. 


\section{Figure 1 Conceptual Model}

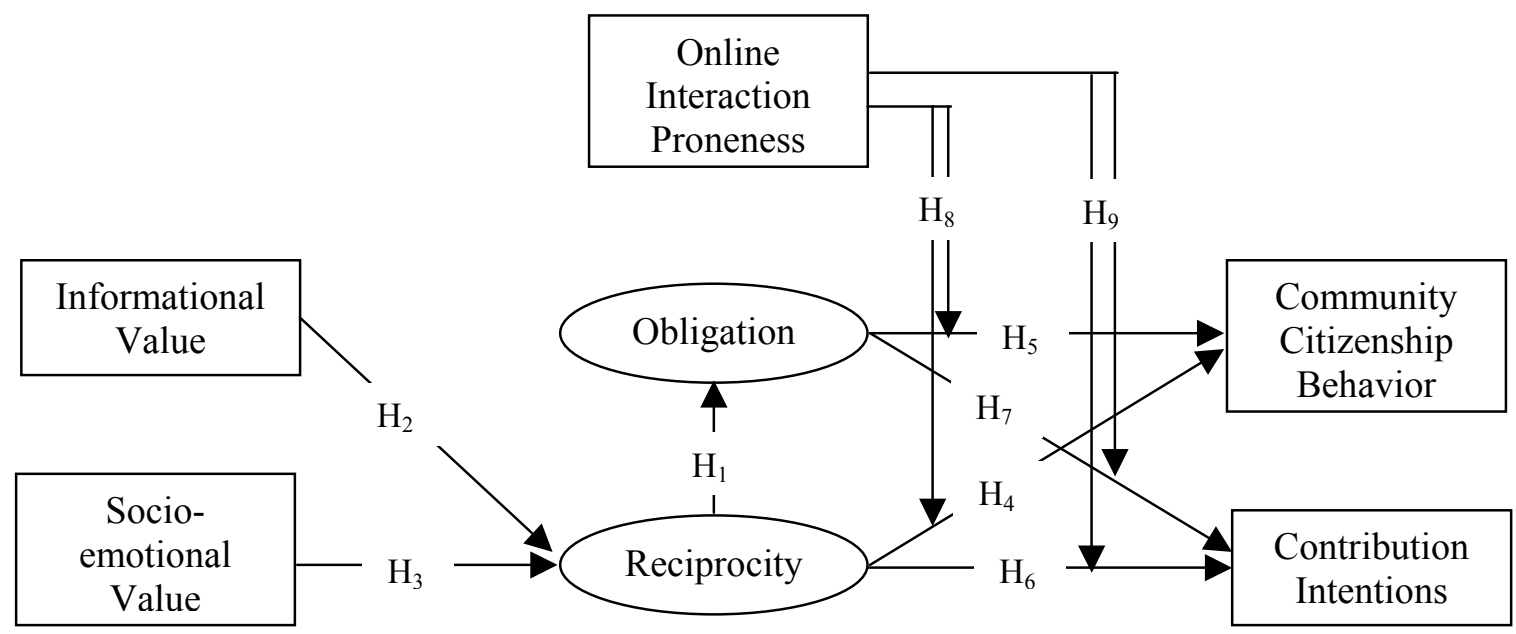




\section{Figure 2 Summary of the Results (Main Effects)}

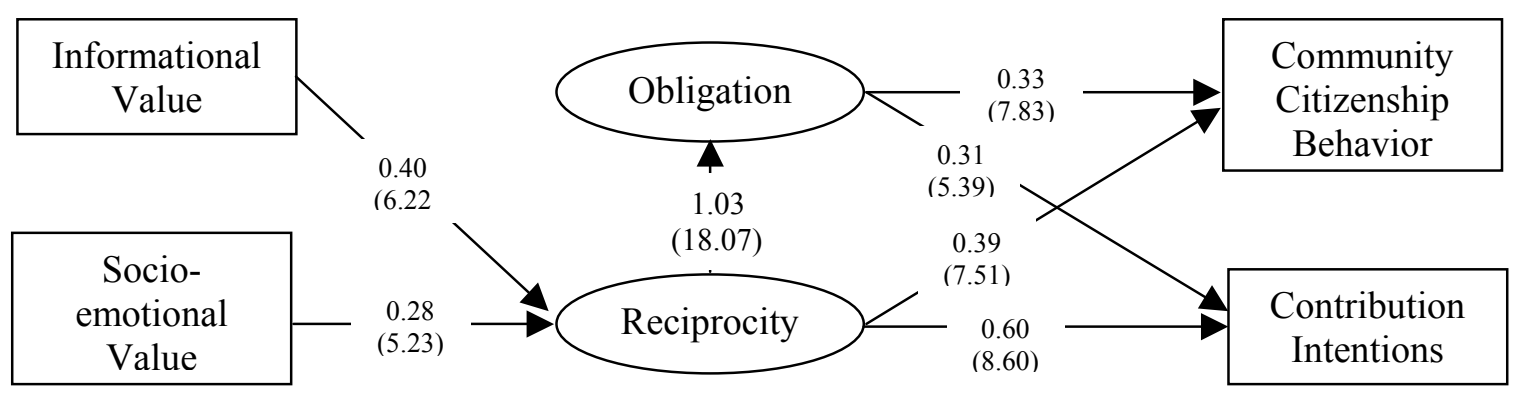


Table 1 Goodness of Fit - CFA Submodels

\begin{tabular}{|lccccc|}
\hline & GFI & AGFI & TLI & CFI & RMSEA \\
\hline Mode101 & 0.94 & 0.90 & 0.96 & 0.97 & 0.076 \\
Mode102 & 0.95 & 0.91 & 0.97 & 0.98 & 0.064 \\
Mode103 & 0.97 & 0.92 & 0.96 & 0.98 & 0.076 \\
\hline
\end{tabular}




\section{Table 2 Results of CFA}

\begin{tabular}{|c|c|c|c|}
\hline Constructs & Reliability & Loadings & t-value \\
\hline Informational Value & 0.89 & & \\
\hline 1. The info provided by the $\mathrm{X}$ community is useful & & 0.85 & 15.41 \\
\hline 2. The info provided by the $\mathrm{X}$ community is of high quality & & 0.87 & 15.99 \\
\hline 3. The info gathered through interaction with members is valuable & & 0.76 & 13.05 \\
\hline 4. The $\mathrm{X}$ community is a great way to get answers to $\mathrm{X}$-related questions & & 0.84 & 14.59 \\
\hline Socio-Emotional Value & 0.86 & & \\
\hline $\begin{array}{l}\text { 1. There is always someone in the } \mathrm{X} \text { community who encourages me when I } \\
\text { am down }\end{array}$ & & 0.84 & 14.87 \\
\hline 2. The emotional support of the other members is valuable & & 0.90 & 16.67 \\
\hline $\begin{array}{l}\text { 3. The other members of the } \mathrm{X} \text { community show understanding for my } \\
\text { concerns }\end{array}$ & & 0.74 & 12.59 \\
\hline Online Interaction Proneness & 0.81 & & \\
\hline 1. I am someone who, given the chance, seeks contact with others online & & 0.68 & 10.81 \\
\hline 2. I like to post messages on the discussion forums & & 0.85 & 14.46 \\
\hline 3. I am someone who enjoys participating in chats & & 0.79 & 13.26 \\
\hline Reciprocity & 0.80 & & \\
\hline 1. Helping fellow members is part of being a X community member & & 0.79 & 12.98 \\
\hline 2. Members should return favors when the X community is in need & & 0.74 & 11.91 \\
\hline 3. When I receive help, I feel it is only right to give back and help others & & 0.71 & 11.27 \\
\hline Obligation & 0.87 & & \\
\hline 1. I feel morally obligated to the $\mathrm{X}$ community. & & 0.77 & 13.09 \\
\hline 2. I feel obligated to help other members when directly asked & & 0.84 & 14.84 \\
\hline 3. It is my duty to help other members when they are in trouble & & 0.88 & 15.75 \\
\hline Helping Behavior (Community Citizenship Behavior) & 0.85 & & \\
\hline 1. I would spend time to help other members with X-related problems & & 0.82 & $----^{\mathrm{a}}$ \\
\hline 2. I am willing to adapt my busy schedule to help other X members & & 0.82 & 13.84 \\
\hline 3. I would assist fellow members in finding solutions to their questions. & & 0.95 & 15.63 \\
\hline Sportsmanship (Community Citizenship Behavior) & 0.61 & & \\
\hline 1. I don't spend a lot of time complaining about trivial matters. & & 0.42 & ------ \\
\hline $\begin{array}{l}\text { 2. I am willing to tolerate minor imperfections in the } \mathrm{X} \text { community if the } \\
\text { overall experience is satisfactory. }\end{array}$ & & 0.41 & 2.74 \\
\hline Civic Virtue (Community Citizenship Behavior) & 0.87 & & \\
\hline 1. I attend the $\mathrm{X}$ community discussions & & 0.84 & ----- \\
\hline 2. I provide suggestions about how the $\mathrm{X}$ community can improve & & 0.87 & 9.28 \\
\hline Contribution Intentions & 0.89 & & \\
\hline 1. I plan to attend events in the $\mathrm{X}$ community in the future & & 0.81 & 13.72 \\
\hline 2. I will definitely contact members of the $\mathrm{X}$ community again & & 0.87 & 15.47 \\
\hline 3. I would consider spending more time in the $\mathrm{X}$ community & & 0.84 & 14.62 \\
\hline
\end{tabular}

${ }^{a}$ For each second order construct in the second order factor analysis, one item is fixed in order to be able to estimate the second order model. 
Table 3 SUR Results Complete Sample

\begin{tabular}{|c|c|c|c|c|c|}
\hline $\mathbf{E q}$ & Relationship & Coeff & t-value & F-value & R-sq adj. \\
\hline (1) & $\begin{array}{l}\text { INFO -> REC } \\
\text { EMO -> REC }\end{array}$ & $\begin{array}{l}0.40 \\
0.28\end{array}$ & $\begin{array}{l}6.22 \\
5.23\end{array}$ & $59.08(\mathrm{p}-0.000)$ & 0.36 \\
\hline (2) & REC -> OBL & 1.03 & 18.07 & $225.65(\mathrm{p}=0.000)$ & 0.52 \\
\hline \multirow[t]{2}{*}{ (3) } & $\mathrm{OBL}->\mathrm{CCB}$ & 0.33 & 7.83 & $197.01(\mathrm{p}=0.000)$ & 0.66 \\
\hline & $\mathrm{REC}->\mathrm{CCB}$ & 0.39 & 7.51 & & \\
\hline \multirow[t]{4}{*}{ (4) } & $\mathrm{OBL}->\mathrm{CONT}$ & 0.31 & 5.39 & $142.56(\mathrm{p}=0.000)$ & 0.58 \\
\hline & REC $->$ CONT & 0.60 & 8.60 & & \\
\hline & & & & System df & 809 \\
\hline & & & & System weighted $R^{2}$ & 0.60 \\
\hline
\end{tabular}


Table 4 Testing for Coincidence, Parallelism, and Equal Elevation

\begin{tabular}{|llll|}
\hline Eq. & Coincidence & Parallelism & Equal elevation \\
\hline$(5)$ & No $\left(\mathrm{F}_{(3,199)}=3.86\right)^{* * *}$ & Yes & No $\left(\mathrm{F}_{(1,199)}=11.60\right)^{* * *}$ \\
$(6)$ & No $\left(\mathrm{F}_{(2,201)}=3.68\right)^{* *}$ & Yes & No $\left(\mathrm{F}_{(1,201)}=6.93\right)^{* * *}$ \\
$(7)$ & Yes & Yes & Yes \\
$(8)$ & No $\left(\mathrm{F}_{(3,199)}=3.87\right)^{* * *}$ & No $\left(\mathrm{F}_{(2,199)}=3.46\right)^{* *}$ & Yes \\
\hline
\end{tabular}

Notes: $\quad{ }^{* * * *}$ significant at the 0.01 level; ${ }^{* *}$ significant at the 0.05 level 